\title{
Paulo Freire e a leitura crítica da Palavramundo no enfrentamento da vulnerabilidade social
}

\author{
Bruna Sola da Silva Ramos* - UFSJ \\ Magda Aparecida Lombardi Ferreira** - UFSJ \\ Lucas Rocha de Brito Rodrigues ${ }^{* * *}$ - UFSJ
}

\section{Resumo}

O presente texto aborda uma experiência extensionista fundamentada na leitura crítica como modo de enfrentamento da vulnerabilidade social que condiciona jovens moradores da periferia de uma cidade do interior de Minas Gerais. Com fundamento teórico-metodológico em Paulo Freire, discutimos a potencialidade da leitura como ato político, que oportuniza o pensamento crítico, e apresentamos os Círculos de Leitura Crítica como instrumento metodológico propício ao posicionamento consciente dos sujeitos diante de sua realidade. Evidenciando uma prática pedagógica orientada pela investigação temática freireana e convergente à leitura problematizadora da palavramundo, trazemos à cena as possibilidades da leitura crítica como caminho para uma compreensão mais profunda da realidade e, por conseguinte, instrumento da luta contra a desumanização.

Palavras-chave: Vulnerabilidade social; Educação problematizadora; Círculos de Leitura Crítica; Paulo Freire.

* Professora Adjunta do Departamento de Ciências da Educação e do Programa de Pós-Graduação em Educação da Universidade Federal de São João del-Rei (UFSJ). Coordenadora da Cátedra Paulo Freire da UFSJ. Líder do Grupo de Estudos Críticos do Discurso Pedagógico. Presidente do Conselho Municipal de Educação de São João del-Rei. brunasola@ufsj.edu.br

** Mestre em Educação pela Universidade Federal de são João del - Rei, Vice coordenadora do Grupo de Estudos Críticos do Discurso Pedagógico. Integra ainda a Cátedra Paulo Freire da Universidade Federal de São João del-Rei. malfe2011@gmail.com

*** Graduando em Pedagogia pela Universidade Federal de São João del-Rei. Desde o início da graduação atuou como bolsista em diferentes ações extensionistas nas áreas de leitura, educação literária, alfabetização e letramentos. rochalucas.r@gmail.com 


\title{
Paulo Freire and the critical reading of The Wordworld in the face of social vulnerability
}

\begin{abstract}
This text deals with an extension experience based on critical reading as a way to face the social vulnerability that conditions young people who live on the outskirts of a city in the inland of Minas Gerais. With a theoretical-methodological foundation in Paulo Freire, we discussed the potentiality of reading as a political act which provides critical thinking and we presented the Critical Reading Circles as a methodological instrument conducive to the conscious positioning of the subjects in the face of their reality. Evidencing a pedagogical practice guided by Freire's thematic research and converging to the problematic reading of the wordworld, we bring to the scene the possibilities of critical reading as a way to a deeper understanding of the reality and, therefore, an instrument in the fight against dehumanization.
\end{abstract}

Key words: Social vulnerability; Problematizing education; Critical Reading Circles; Paulo Freire

\section{Paulo Freire y la lectura crítica de La Palabra- mundo en el enfrentamiento de la vulnerabilidad social}

\section{Resumen}

El presente texto aborda una experiencia de extensión universitaria basada en la lectura crítica como modo de enfrentamiento de la vulnerabilidad social que condiciona jóvenes habitantes de las periferias de una ciudad en el interior de Minas Gerais. Con fundamento teórico y metodológico en Paulo Freire, proponemos la lectura como acto político que favorece el pensamiento crítico y planteamos los Círculos de Lectura Crítica como instrumento metodológico propicio al posicionamiento consciente de los sujetos delante de su realidad. Evidenciamos una práctica pedagógica orientada hacia la investigación temática freireana de la lectura crítica como camino para una comprensión más profunda de la realidad y, por lo tanto, instrumento de lucha en contra de la deshumanización.

Palabras clave: Vulnerabilidad social; Educación problematizadora; Círculos de Lectura Crítica; Paulo Freire. 


\section{Notas introdutórias}

$$
\begin{array}{r}
\text { "Com a palavra, o homem se faz homem. Ao dizer a } \\
\text { sua palavra, pois, o homem assume conscientemente } \\
\text { sua essencial condição humana". } \\
\text { Paulo Freire }
\end{array}
$$

Palavra. Consciência. Condição humana. Com Paulo Freire (1987, p. 44), trazemos à luz a força e a vitalidade da palavra, já que "existir, humanamente, é pronunciar o mundo". Ao pronunciar o mundo, crítica e responsivamente, homens e mulheres vão se constituindo na transitividade de suas consciências, o que lhes permite ir além das formas ingênuas de compreender este mundo - essencialmente pautadas na mitificação da realidade - e perceberem-se "corpos conscientes"; sujeitos, cujas consciências intencionadas ao mundo captam a realidade da qual fazem parte e sobre a qual se debruçam em vida.

Esse pensamento nos leva à assunção freireana de um sujeito histórico, que busca superar sua consciência ingênua e construir, em si e com os demais, uma consciência, a qual se faça instrumento de sua intervenção no mundo. Para isso, somos instados a compreender a leitura como prática social, que oferece ao sujeito a possibilidade de uma inserção cada vez mais consciente na realidade vivida, o que amplia as suas possibilidades de se posicionar reflexivamente diante dela e, quiçá, transformá-la.

É nesse cenário que tratamos a opressão vivida por crianças e adolescentes em situação de vulnerabilidade social, como uma das mais duras opressões a que são submetidos. Onde está a vulnerabilidade, encontra-se, também, o risco. Vulnerare: ferir, penetrar, em raiz latina. Risco de ferir nossa infância e juventude; imagem do que seremos em devir. Risco de ferir os próprios direitos humanos ao ser-lhes negado aquilo que é próprio de sua humanidade: o direito a viver uma vida digna e boa.

Com esse panorama em tela, tratamos, mais amiúde, de sujeitos de seis a 17 anos de idade, moradores da periferia de uma cidade 
do interior de Minas Gerais e em situação de vulnerabilidade social, atendidos por uma associação civil que lhes oferece apoio escolar e alimentar, vivências artísticas e culturais, orientação e formação profissional, e, sobretudo, acolhimento e respeito.

No contexto dessa associação, desenvolvemos, com 30 crianças e jovens situados em condição de vulnerabilidade social, um projeto de extensão ${ }^{1}$ voltado à promoção da leitura crítica como instrumento de uma compreensão mais ativa e profunda da realidade em que vivem. Com fundamento em Paulo Freire, o que nos moveu neste projeto foi a possibilidade de construir junto com esses jovens sujeitos uma forma outra de ler a palavra e ler o mundo, vivenciando a leitura como uma "experiência dialógica" (FREIRE, 2012, p. 81), em movimentos de reflexão coletiva, de colaboração e diálogo; e, por meio deles, produzir sentidos outros, trocar saberes, despertar e oportunizar o pensamento crítico tão necessário para o enfrentamento da própria realidade.

Dessa maneira, o presente texto é fruto da referida ação extensionista e objetiva apresentar e discutir o movimento de leitura crítica constituído em um dos grupos de trabalho, composto especificamente por nove estudantes com idades entre nove e 12 anos. O pensamento de Paulo Freire é o referencial teórico-metodológico que nos orientou na compreensão das relações entre o ato de ler e a formação do pensamento crítico, bem como a criação e o desenvolvimento dos chamados Círculos de Leitura Crítica, o que será objeto de nossa análise ao longo do texto. Ainda quanto à composição do artigo, evidenciamos como corpus de análise dados do perfil dos jovens obtidos a partir da aplicação de questionário socioeconômico, trechos de notas de campo elaboradas pelo educador/bolsista, que atuou no projeto, e texto produzido no decorrer das atividades de leitura propostas. A fim de preservar o anonimato dos participantes do projeto, seus nomes foram alterados nos excertos apresentados.

Junto a Larrosa (2014, p. 28), invocamos a perspectiva da "experiência” como "aquilo que 'nos passa', ou que nos toca, ou

Projeto financiado pelo Programa Institucional de Bolsas de Extensão - PIBEX. 
que nos acontece, e, ao nos passar, nos forma e nos transforma”, requerendo de nós um gesto de interrupção: parar para pensar, olhar e sentir. No dizer do autor, "a experiência não é o caminho até um objetivo previsto, até uma meta que se conhece de antemão, mas é uma abertura para o desconhecido" (LARROSA, 2014, p. 34). Dizer da experiência de leitura por nós vivida, como abertura ao desconhecido, é entendê-la com base na experiência freireana: como um ato político e responsivo, revelador de nossa inquietação como educadoras e educadores populares preocupados com a formação do sujeito crítico - um sujeito que ressignifique sua leitura da "palavramundo" (FREIRE, 2003, p.12), para ser capaz de produzir uma nova pronúncia da realidade.

\section{Vulnerabilidade social e leitura crítica}

[...] Várias viaturas subiram a rua do Projeto com a sirene ligada, o que levou todos os alunos a irem à janela e começarem a contar, todos juntos, casos sobre polícia. Aproveitamos do assunto e conversamos sobre polícia: se a consideravam boa ou má, como a viam, se já estiveram com um policial. Vinicius contou [...] que um policial já havia apontado uma arma de fogo para ele numa operação em seu bairro, pois sua casa é próxima a um ponto de narcotráfico. Luís, outra criança, contou que já teve sua casa assaltada três vezes. Após alguns minutos, recebemos a notícia de que a polícia estava se dirigindo a um bar na rua do Projeto, porque um homem havia assassinado sua esposa. Tocou-me muito quando Henrique contou-nos sobre sua família. Ele tem 11 anos, sua mãe está presa por latrocínio num anexo do presídio [...] próximo ao Projeto, e seu pai está preso também por roubo. Nem eu nem minha colega sabíamos o que significava latrocínio, e Henrique, talvez por perceber nossa ignorância, perguntou-nos se sabíamos o que era e ao falarmos que não, explicou-nos: é roubo seguido de morte (DIÁRIO DE CAMPO, 16/03/2017).

Violência, agressão contra a mulher, tráfico de drogas, privação de liberdade, relações opressores-oprimidos e infâncias "roubadas" são alguns dos sentidos construídos a partir da leitura da epígrafe, uma passagem do diário de campo escrito no desenrolar do projeto de extensão, que nos ajuda a compreender a vulnerabi- 
lidade condicionadora da realidade de vida dos jovens com quem dialogamos. Sentidos que se constroem como marcas dos processos de desumanização e de negação que, historicamente, experienciam. Sentidos de uma realidade agressiva em que "a violência é a constante e a convivência das pessoas é muito maior com a morte do que com a vida [...]" (FREIRE, 2014, p. 32).

Desse modo, ao buscarmos elementos para compreender a vulnerabilidade social dos sujeitos com quem interagimos em ação extensionista, entendemos que não nos bastava desvelar as camadas mais visíveis de sua significação como sujeitos que habitam as periferias e que, portanto, são vistos como "moradores de áreas que carecem de infraestrutura sanitária, moradia e congregam o maior contingente de pessoas em estado de carência total" (ASSOCIAÇÃO VIDA NOVA, s/d, s/p). Necessariamente, aprendemos a nos perguntar ao longo do processo: quem são essas crianças e jovens? Quais são suas "leituras de mundo"? Que vulnerabilidades os condicionam?

Ao delinearmos um olhar questionador para a situação de vulnerabilidade social desses jovens, pudemos (re)compor o panorama de exclusão a que estão diretamente vinculados. Segundo levantamento de dados a partir de questionário socioeconômico aplicado aos participantes do projeto, descobrimos que, entre os nove jovens que participaram do grupo delimitado neste artigo: oito são negros/negras, cinco possuem pai e/ ou mãe detentos, oito possuem pai e/ou mãe com apenas ensino fundamental e cinco são filhos/filhas de faxineiras e empregadas domésticas.

Isso nos leva a problematizar que, comumente, se percebe a vulnerabilidade social ligada à pobreza material. Todavia, segundo Oliveira (apud TEIXEIRA, 2015, p. 47), a vulnerabilidade social "não se restringe à categoria econômica, mas perpassa organizações políticas, de raça, orientação sexual, gênero, etnia”. Para Rado e Boneti (2009), problematizar o conceito de vulnerabilidade social pode ser uma ferramenta estratégica para entendermos a situação de pessoas em exclusão social, porque, ao explorarmos o conceito, 
podemos perceber amplamente vicissitudes e idiossincrasias existentes nas vivências dessas pessoas, que vão muito além dos atributos de renda.

Os dados que pudemos construir acerca dos sujeitos nos revelaram uma vulnerabilidade que vai muito além da pobreza e da carência de infraestrutura em seus locais de moradia, pois são frutos da desumanização como possibilidade histórica (FREIRE, 1987). Desumanização a que estão expostos por serem negros, pobres, habitantes da periferia; filhos e filhas da classe operária, convivendo, diariamente, com as mazelas da pobreza, da violência, do direito à educação negado e do trabalho precarizado. Com fundamento em Paulo Freire (1987), portanto, assumimos que a vulnerabilidade social não é condição do sujeito, mas situação social fruto de uma "ordem" injusta e opressora que fere a vocação ontológica do sujeito de ser mais.

Nesse cenário, entendemos, junto com Teixeira (2015. p. 48), que a vulnerabilidade social não deve ser analisada "[...] por meio de um único referencial, devido a essa poder ser determinada por aspectos próprios a cada sujeito e pelas condições do seu entorno". As vulnerabilidades são muitas, os sujeitos em situação de vulnerabilidade são muitos e não podem ser vistos por apenas um espectro. Deve-se, portanto, pensar quem são os sujeitos tidos vulneráveis, "onde estão, o que fazem, quais as condições de vida, quais as possibilidades que encontram e qual a visão que temos, enquanto sociedade, sobre eles" (TEIXEIRA, 2015, p.48).

Para Adorno (2001, p. 12), o termo vulnerabilidade representa não apenas um novo modo de expressar um velho problema, mas, principalmente, "a construção de uma nova mentalidade [...] uma busca por mudança no modo de encarar as populações-alvo dos programas sociais". Contudo, como se nota na denúncia apontada por Lopes et al. (2008, p. 66), ainda temos prestado assistência a essa população vulnerável na perspectiva do "fazer o bem ao próximo", uma "cultura de dádiva e benemerência" em ações centradas no nível institucional, "pouco avançando para a dimensão territorial, para a inserção comunitária". 
Daí, depreende-se a importância da ação socioeducativa que realizamos junto à comunidade da qual fazemos parte, favorecendo as oportunidades de promoção da leitura crítica de crianças e jovens situados em perspectiva de vulnerabilidade social e amparados por uma associação que busca lhes oferecer ampliação de seus espaços de domínio vital. Acreditamos que o fortalecimento da leitura crítica seja um significativo modo de enfrentamento da vulnerabilidade que atinge essas crianças e jovens, na perspectiva da expansão de seu universo conceitual, simbólico, social, político e ético, ampliando suas possibilidades de ler a palavra e ler o mundo à sua volta (FREIRE, 2003).

Em suas obras, Paulo Freire defende, incansavelmente, a importância do ato de ler não como uma repetição mecânica de palavras e frases, mas como uma ação que implica sempre a percepção crítica, a interpretação e a "re-escrita" do lido. Dito de outra forma, o conhecimento verdadeiro só virá pela apreensão da leitura crítica. Leitura que fará com que o indivíduo se posicione politicamente diante da sua realidade, se reconheça e se constitua como sujeito no mundo; portanto, responsável pela construção deste mundo.

Como afirma Freire (2003, p. 11), linguagem e realidade se prendem dinamicamente e, por isso, "a compreensão do texto a ser alcançada por sua leitura crítica implica a percepção das relações entre o texto e o contexto". Texto e contexto são conceitos que ocupam lugar de destaque nas escrituras freireanas. O sentido do texto não está apenas no texto, mas no contexto em que ele foi criado, bem como no contexto em que ele é lido. Tanto no momento da escrita quanto no da leitura, o sentido dado ao texto sofre influências das situações que os sujeitos, escritores e leitores, vivenciaram anteriormente e que armazenaram em suas memórias, formando, assim, suas leituras de mundo.

Freire (2003) nos diz que, para refletirmos sobre um texto, não podemos isolá-lo do contexto; ao contrário, temos que relacioná-lo com outros textos, com nossos saberes, com nossos pensares, com nossas memórias, com nossos conhecimentos. Vamos ao texto, com 
olhos abertos, carregados de uma curiosidade epistemológica; um antídoto das certezas, que nos impulsiona, que nos movimenta, e esse movimento só acontece por meio de uma educação que valorize a reflexão e que forme um ser crítico, questionador e transformador de sua própria realidade (VASCONCELOS; BRITO, 2014).

Na perspectiva de Paulo Freire (1992),

Ler um texto não é 'passear' licenciosamente, pachorrentamente, sobre as palavras. É apreender como se dão as relações entre as palavras na composição do discurso. É tarefa do sujeito crítico, humilde, determinado. Ler, enquanto estudo, é um processo difícil, até penoso, às vezes, mas sempre prazeroso também. Implica que o(a) leitor(a) se adentre na intimidade do texto para apreender sua mais profunda significação. (p.40)

Trabalhar a formação do leitor crítico, portanto, é trabalhar a formação do indivíduo livre, pensante, emancipado. É dar ao sujeito condições de adquirir conhecimento e ampliar sua capacidade produtiva e comunicativa, fazendo das palavras ponte entre a linguagem e a vida, uma vez que produzir um texto ou ler um texto é dialogar com outrem, é estabelecer um vínculo entre o sujeito e o mundo onde se vive. Assim, para Paulo Freire (2012, p. 60), não se pode ler autenticamente se não se assume "a forma crítica de ser ou estar sendo sujeito da curiosidade, sujeito da leitura, sujeito do processo de conhecer em que se acha".

Abramo (1997, p. 33) indica que, enquanto os jovens em situação de vulnerabilidade social forem vistos como "a encarnação de impossibilidades", não poderão ser vistos, ouvidos ou entendidos como sujeitos que apresentam suas próprias questões. Nossa pretensão, portanto, foi desenvolver uma ação extensionista em que os jovens fossem vistos, ouvidos e entendidos como sujeitos, criando, com eles e com elas, novas possibilidades de leitura, que lhes permitam esperançar por uma realidade menos injusta e mais humana.

\section{A formação leitora nos círculos de leitura crítica}

Inspirados por Paulo Freire (1987) e seus Círculos de Cultura, organizamos como proposta metodológica o que convencio- 
namos chamar de Círculos de Leitura Crítica: espaços de circulação de saberes, abertos ao convívio, organizados em formato de roda e marcados pela horizontalidade das relações, nos quais buscamos o diálogo com textos de diferentes gêneros, a discussão aberta e o acolhimento às diferentes leituras de mundo e aos modos múltiplos e singulares de leitura da palavra.

Nos Círculos de Leitura Crítica, nossa aposta é na leitura reflexiva como caminho para compreendermos a realidade, pois, como afirma Freire (2003, p. 11), "a compreensão do texto a ser alcançada por sua leitura crítica implica a percepção das relações entre o texto e o contexto". Assim, Freire (2003, p. 21) amplia o ato de ler e o coloca como um ato político, um ato de conhecimento, um ato de desalienação, que "implica sempre percepção crítica, interpretação e 're-escrita' do lido".

Dessa forma, a metodologia dos Círulos de Leitura Crítica muda o foco da leitura mecânica e do processo de decodificação de palavras para uma abordagem que seja capaz de desafiar a reflexão crítica, estabelecendo uma conexão do texto lido com a realidade vivida pelo sujeito leitor. Sob essa perspectiva, intenciona superar a leitura superficial, muitas vezes reduzida ao mero lidar com perguntas e respostas sobre o texto lido. O leitor crítico traz para o texto o mundo que ele lê e como o apreende dentro do contexto histórico em que vive, de modo a reescrever o lido (e também o vivido) a partir da construção de sentidos próprios e múltiplos.

Em busca de superar o paradigma de uma formação leitora mecânica, decodificadora e, muitas vezes, limitada à interpretação do pensamento do autor, os Círculos de Leitura Crítica se fundamentam em uma prática pedagógica que converge para a problematização do lido, por meio da reflexão crítica sobre o texto. É nesse sentido que defendemos, junto a Paulo Freire (2012, p. 81), a leitura como uma experiência dialógica, "em que a discussão do texto realizada por sujeitos leitores esclarece, ilumina e cria a compreensão grupal do lido". Em grupo, a emergência de diferentes pontos de vista, que se vão expondo uns aos outros, contribui para enriquecer o que Freire (2012, p. 81) chama de "produção da inteligência do texto". 
Dessa maneira, seguindo os princípios freireanos, os debates desenvolvidos nos Círculos de Leitura Crítica são geradores de múltiplos sentidos, em busca de que o leitor e a leitora possam criar seus próprios textos com base no que foi lido ao refletirem/refratarem a ideia apresentada pelo autor. Fazemos, assim, uma leitura que extrapola os limites do texto, que permite aos leitores construírem relações entre a leitura de mundo que possuem e a leitura do texto que lhes é apresentado.

Entendemos, portanto, que os Círculos de Leitura Crítica oferecem uma possibilidade de desvelar a realidade por meio dos textos que nos são apresentados cotidianamente na escola ou fora dela. Para nós, a leitura crítica é um instrumento que potencializa a conscientização, por meio da combinação dos saberes que leitores e leitoras trazem consigo e da reflexão que fazem do texto, oportunizando o debate sobre o mundo que os rodeia.

No interior do projeto de extensão desenvolvido, tendo em vista a perspectiva da educação problematizadora, o caminho para a efetivação de nossa proposta de leitura crítica foi a investigação temática da realidade dos educandos e das educandas. De acordo com Freire (1987, p. 50), investigar o tema gerador é investigar "o seu pensamento-linguagem referido à realidade, os níveis de sua percepção desta realidade, a sua visão do mundo". Desse modo, em uma ação que buscou contínua troca de saberes, sem imposições ou prescrições com relação às temáticas trabalhadas, foi feito um amplo movimento de descoberta e levantamento de temas, os quais emergiram da realidade concreta dos sujeitos envolvidos. Praticando a busca da coerência entre a fala e a escuta dialógica, por meio de questionamentos, debates e percepções, que foram sendo construídos a partir das enunciações e posicionamentos assumidos pelos participantes, partimos ao encontro das "situações-limite" vivenciadas pelos jovens sujeitos, para que se evidenciassem as temáticas geradoras a serem problematizadas no diálogo.

Em Freire (1987, p. 51), as situações-limite são definidas como as "dimensões concretas e históricas de uma dada realida- 
de", que se apresentam como desafiadoras a homens e mulheres. São, em nossa leitura, os desafios e problemas que desumanizam os sujeitos e que, por isso, necessitam ser superados. Assim, nosso trabalho de extensão se comprometeu a perceber diferentes situações-limite dos jovens em vulnerabilidade social e, a partir da leitura, provocar e agitar as possibilidades de enfrentamento da vulnerabilidade social a eles imposta.

As situações-limite foram codificadas por meio de temas geradores desvelados através de um caminho de investigação, que explicitaremos no quadro a seguir, como proposta de sistematização, possibilitando um panorama sucinto do trabalho realizado nos Círculos de Leitura Crítica. Neste quadro estão elencados os temas que emergiram da realidade dos sujeitos e que foram abordados, a partir de textos de diferentes gêneros, no movimento de construção coletiva de problematizações sobre o lido/vivido.

\begin{tabular}{|c|c|c|c|}
\hline $\begin{array}{l}\text { Encontros dos } \\
\text { Círculo de } \\
\text { Leitura Crítica }\end{array}$ & $\begin{array}{l}\text { Temática/ Tema } \\
\text { gerador proposto }\end{array}$ & $\begin{array}{l}\text { Gêneros textuais } \\
\text { trabalhados }\end{array}$ & Problematizações construídas no coletivo \\
\hline 1 & \multirow{5}{*}{$\begin{array}{l}\text { Aproximações } \\
\text { iniciais - } \\
\text { movimentos de } \\
\text { escuta }\end{array}$} & \multirow{5}{*}{$\begin{array}{l}\text { Texto informativo } \\
\text { Música } \\
\text { Fanzine } \\
\text { Charadas } \\
\text { Reportagem de } \\
\text { jornal } \\
\text { Poesia } \\
\text { Mensagem }\end{array}$} & \multirow{5}{*}{$\begin{array}{l}\text { Quem sou eu? } \\
\text { De onde venho? } \\
\text { Quais são meus interesses? } \\
\text { Que histórias trago para compartilhar? } \\
\text { Que diferenças existem entre os sujeitos? } \\
\text { Que livros já li? } \\
\text { O que mais me marcou nas leituras que já fiz? } \\
\text { Como a leitura me ajuda a "ver" melhor o } \\
\text { mundo ao meu redor? } \\
\text { Como um mesmo assunto pode ser significa- } \\
\text { do de formas diferentes? }\end{array}$} \\
\hline 2 & & & \\
\hline 3 & & & \\
\hline 4 & & & \\
\hline 5 & & & \\
\hline 6 & Trabalho & $\begin{array}{l}\text { Charges } \\
\text { Imagens } \\
\text { Poesia }\end{array}$ & $\begin{array}{l}\text { Por que existe um dia do(a) trabalhador(a)? } \\
\text { O que é o trabalho? } \\
\text { Com o que intencionam trabalhar? } \\
\text { Como o trabalho pode modificar o seu } \\
\text { mundo? } \\
\text { Para que servem as leis trabalhistas? } \\
\text { O que é o salário mínimo? Para que serve? } \\
\text { Quem recebe? O salário mínimo é justo? } \\
\text { Há trabalhos considerados mais importantes } \\
\text { que outros? } \\
\text { Por que uns ganham mais do que outros? } \\
\text { O que é trabalho escravo? }\end{array}$ \\
\hline
\end{tabular}




\begin{tabular}{|c|c|c|c|}
\hline $\begin{array}{l}\text { Encontros dos } \\
\text { Círculo de } \\
\text { Leitura Crítica }\end{array}$ & $\begin{array}{l}\text { Temática/ Tema } \\
\text { gerador proposto }\end{array}$ & $\begin{array}{l}\text { Gêneros textuais } \\
\text { trabalhados }\end{array}$ & Problematizações construídas no coletivo \\
\hline 7 & \multirow{5}{*}{$\begin{array}{l}\text { Moradia - visita } \\
\text { ao planetário da } \\
\text { cidade }\end{array}$} & \multirow{5}{*}{$\begin{array}{l}\text { Animação audio- } \\
\text { visual } \\
\text { Desenho } \\
\text { Imagens de casas } \\
\text { Classificados de } \\
\text { jornais } \\
\text { Poesia } \\
\text { Desenho } \\
\text { Capa de livreto }\end{array}$} & \multirow{5}{*}{$\begin{array}{l}\text { Moramos todos nos mesmos lugares? } \\
\text { Que lugares compartilhamos? } \\
\text { Quais são as nossas moradias? } \\
\text { Como é o lugar onde vivemos? } \\
\text { O planeta é uma casa? } \\
\text { Quais as singularidades do nosso planeta? } \\
\text { Quem compartilha o espaço comigo? } \\
\text { O que é uma casa? Todos têm casa? } \\
\text { Nós moramos em nossas casas? } \\
\text { Qual a função da casa? } \\
\text { Do que a casa é feita? } \\
\text { A cidade é nossa casa? } \\
\text { Como é a nossa casa? } \\
\text { Todas as casas são iguais? } \\
\text { É possível morar em mais de uma casa? } \\
\text { Como cuidamos de nossa casa? } \\
\text { Por que alguns moram em casas muito ricas e } \\
\text { outros em casas muito pobres? } \\
\text { Por que existem pessoas sem casa? }\end{array}$} \\
\hline 8 & & & \\
\hline 9 & & & \\
\hline 10 & & & \\
\hline 11 & & & \\
\hline 12 & Cidade e bairro & $\begin{array}{l}\text { Crônica } \\
\text { Música } \\
\text { Cartazes }\end{array}$ & $\begin{array}{l}\text { Quais as histórias e singularidades de nossa } \\
\text { cidade? } \\
\text { Quais as histórias e singularidades de nossos } \\
\text { bairros? } \\
\text { Quem são as pessoas que moram nos nossos } \\
\text { bairros? } \\
\text { Quais são os problemas que enfrentamos nos } \\
\text { bairros onde vivemos? } \\
\text { Quais são as qualidades de nossos locais de } \\
\text { moradia? } \\
\text { O que podemos fazer para melhorar nossa } \\
\text { cidade e bairro? }\end{array}$ \\
\hline 13 & \multirow[t]{2}{*}{ Convivência } & \multirow[t]{2}{*}{$\begin{array}{l}\text { Entrevista } \\
\text { Fábula } \\
\text { Reportagem } \\
\text { audiovisual }\end{array}$} & \multirow{2}{*}{$\begin{array}{l}\text { Qual a importância do convívio? } \\
\text { Como podemos lidar com as diferenças? } \\
\text { É possível conviver bem? } \\
\text { O que podemos fazer para melhorar a convi- } \\
\text { vência com as pessoas? } \\
\text { Quais os aspectos negativos da convivência e } \\
\text { os desafios na relação com o outro? } \\
\text { Quais os aspectos positivos da convivência? } \\
\text { Que acordos individuais e coletivos podem } \\
\text { se estabelecer em nossa convivência para } \\
\text { melhor convivermos? }\end{array}$} \\
\hline 14 & & & \\
\hline 15 & $\begin{array}{l}\text { Avaliação dos } \\
\text { encontros }\end{array}$ & $\begin{array}{l}\text { Avaliação oral } \\
\text { Avaliação escrita }\end{array}$ & $\begin{array}{l}\text { Quais aspectos positivos e negativos dos } \\
\text { círculos? } \\
\text { O que mais agradou? } \\
\text { O que desagradou? } \\
\text { Quais as sugestões de melhorias? }\end{array}$ \\
\hline
\end{tabular}




\begin{tabular}{|c|c|c|c|}
\hline $\begin{array}{l}\text { Encontros dos } \\
\text { Círculo de } \\
\text { Leitura Crítica }\end{array}$ & $\begin{array}{l}\text { Temática/ Tema } \\
\text { gerador proposto }\end{array}$ & $\begin{array}{l}\text { Gêneros textuais } \\
\text { trabalhados }\end{array}$ & Problematizações construídas no coletivo \\
\hline 16 & $\begin{array}{l}\text { Férias/Retomada } \\
\text { dos círculos }\end{array}$ & $\begin{array}{l}\text { Cantiga } \\
\text { Texto informativo } \\
\text { sobre o folclore } \\
\text { e a história da } \\
\text { cantiga }\end{array}$ & $\begin{array}{l}\text { Quais experiências de férias queremos } \\
\text { compartilhar? Como é retornar ao círculo } \\
\text { de leitura? } \\
\text { O que foi lido durante as férias? } \\
\text { De quais temas me lembro de havermos } \\
\text { trabalhados até o momento? }\end{array}$ \\
\hline 17 & \multirow[t]{2}{*}{$\begin{array}{l}\text { Condições de } \\
\text { infraestrutura/ } \\
\text { Qualidade de vida }\end{array}$} & \multirow[t]{2}{*}{$\begin{array}{l}\text { Notícias de jornais } \\
\text { Narrativa oral } \\
\text { Texto dissertativo }\end{array}$} & \multirow{2}{*}{$\begin{array}{l}\text { Existem diferenças nas condições de infraes- } \\
\text { trutura de cada bairro? } \\
\text { A quem se deve a responsabilidade da } \\
\text { infraestrutura dos bairros? } \\
\text { Por que necessitamos de uma boa condição } \\
\text { de infraestrutura? } \\
\text { Em que nos prejudica uma infraestrutura má? } \\
\text { O que é viver dignamente? } \\
\text { O que você faria se fosse algum representante } \\
\text { do governo diante do problema apontado em } \\
\text { seu bairro? } \\
\text { O que é responsabilidade? } \\
\text { O que é cidadania? } \\
\text { Como posso ajudar a mudar as condições de } \\
\text { infraestrutura do meu entorno? }\end{array}$} \\
\hline 18 & & & \\
\hline 19 & \multirow[t]{2}{*}{$\begin{array}{l}\text { Organização da bi- } \\
\text { blioteca do Projeto } \\
\text { - visita à biblioteca } \\
\text { municipal }\end{array}$} & \multirow[t]{2}{*}{ Imagens } & \multirow{2}{*}{$\begin{array}{l}\text { O que é uma biblioteca? } \\
\text { Qual a importância das bibliotecas? } \\
\text { Quais os processos de organização de uma } \\
\text { biblioteca? } \\
\text { Quem tem acesso a uma biblioteca? } \\
\text { Já visitamos alguma biblioteca? } \\
\text { Como uma biblioteca funciona? } \\
\text { O que significam os nomes das bibliotecas? } \\
\text { Conhecem as bibliotecas da cidade? }\end{array}$} \\
\hline 20 & & & \\
\hline 21 & \multirow[t]{5}{*}{$\begin{array}{l}\text { Condições de } \\
\text { infraestrutura }\end{array}$} & \multirow{5}{*}{$\begin{array}{l}\text { Carta } \\
\text { Livro de poemas } \\
\text { (voltado a crian- } \\
\text { ças) } \\
\text { Histórias contadas }\end{array}$} & \multirow{5}{*}{$\begin{array}{l}\text { O que é uma carta? } \\
\text { Para que serve uma carta? } \\
\text { Quem escreve uma carta? } \\
\text { Já enviou e/ou recebeu cartas? } \\
\text { Que sentidos emergem da Carta Universal } \\
\text { dos Direitos Humanos? } \\
\text { Se uma criança pudesse escrever uma carta } \\
\text { ao prefeito, denunciando os problemas de } \\
\text { infraestrutura de seu bairro, o que ela diria? } \\
\text { O que você quer dizer ao prefeito de sua } \\
\text { cidade sobre as condições de infraestrutura } \\
\text { de seu bairro? } \\
\text { Quais os direitos das crianças na cidade? } \\
\text { Bibliotecas fazem parte da infraestrutura de } \\
\text { uma cidade? }\end{array}$} \\
\hline 22 & & & \\
\hline 23 & & & \\
\hline 24 & & & \\
\hline 25 & & & \\
\hline
\end{tabular}




\begin{tabular}{|c|c|c|c|}
\hline $\begin{array}{l}\text { Encontros dos } \\
\text { Círculo de } \\
\text { Leitura Crítica }\end{array}$ & $\begin{array}{l}\text { Temática/ Tema } \\
\text { gerador proposto }\end{array}$ & $\begin{array}{l}\text { Gêneros textuais } \\
\text { trabalhados }\end{array}$ & Problematizações construídas no coletivo \\
\hline 26 & \multirow{3}{*}{$\begin{array}{l}\text { Violências - de- } \\
\text { núncias e anúncios } \\
\text { de superações }\end{array}$} & \multirow{3}{*}{$\begin{array}{l}\text { Imagens } \\
\text { Imagens escolhi- } \\
\text { das pelas crianças } \\
\text { sobre bullying, } \\
\text { violência domés- } \\
\text { tica, violência } \\
\text { contra animais e } \\
\text { racismo. } \\
\text { Letra de música } \\
\text { Texto ético/ } \\
\text { estético }\end{array}$} & \multirow{3}{*}{$\begin{array}{l}\text { Que tipos de violências conhecemos? } \\
\text { Onde encontramos a violência? } \\
\text { Por que existem violências? } \\
\text { Quem pratica violências? } \\
\text { Somos violentos? } \\
\text { Como a violência está presente em nossa } \\
\text { cotidianidade? Quem provoca a violência? } \\
\text { Quais os efeitos da violência a curto e a } \\
\text { longo prazos? Podemos evitar a violência? } \\
\text { Como? } \\
\text { Como a situação de violência vivida pode ser } \\
\text { superada? } \\
\text { Qual é a representação desse anúncio de } \\
\text { superacão? }\end{array}$} \\
\hline 27 & & & \\
\hline 28 & & & \\
\hline
\end{tabular}

Fonte: quadro elaborado pelo grupo extensionista.

Podemos observar, no quadro, que há um encadeamento de temas iniciado com a realização de aproximações iniciais ou encontros para levantamento de universo temático (FREIRE, 1987). A partir do movimento de escuta a que nos propusemos nesses encontros de aproximações iniciais e ao longo o desenvolvimento do trabalho, foi possível identificar seis temas geradores, que foram desenvolvidos ao longo dos encontros: trabalho, moradia, cidade, bairro, condições de infraestrutura e violência(s).

Também, como se pode aferir no quadro exposto, os temas foram perpassados por textos de diferentes gêneros, que serviram como disparadores das discussões, mas também como vozes que nos auxiliaram nos exercícios de problematização desenvolvidos. Ao longo do processo de levantamento dos temas a serem problematizados, foram selecionados textos de diferentes gêneros, que estabeleciam uma conexão com o mundo real e se mostravam relevantes para a vida desses jovens; gêneros, tais como crônicas, textos jornalísticos, poesias, romances juvenis, poemas e até as pichações fotografadas nos muros da cidade, a partir dos quais propusemos o exercício de compreensão reflexiva. 
A dinâmica de leitura envolvia momentos distintos: (1) apresentação e questionamentos sobre o gênero do texto lido (Conheciam o gênero? Em que situação tiveram contato com ele? Quais as suas características?); (2) leitura silenciosa do texto; (3) leitura coletiva, que se repetia conforme a necessidade de fluição da leitura; (4) jograis de leitura, em que os estudantes se alternavam na leitura em voz alta; (5) debate, problematização e compreensão do texto em suas relações com o tema em debate e com o contexto de vida dos jovens leitores ${ }^{2}$.

Notas de diário de campo registradas pelo bolsista da extensão durante o desenvolvimento da experiência nos auxiliam a alçar uma melhor compreensão de nossa aposta na formação leitora crítica. Em uma dessas notas, escrita quando o tema gerador "Condições de infraestrutura" nos bairros estava sendo trabalhado, evidenciamos o movimento de problematização que perpassou os encontros:

[...] Tentamos provocar: 'De quem é a culpa de estar assim?' 'Ah, a culpa é do prefeito.', respondeu Olívia. 'Por que do prefeito?', perguntei. 'Porque ele quer gastar com outras coisas.', ela disse. 'Que coisas?', eu insisti. 'Ah, tipo carro, casa. Minha avó que falou.' Continuei as provocações. Gustavo, observando a imagem do buraco que também estava colada, disse que era preciso cuidar da cidade, porque senão 'no futuro, não terá nada direito'. Perguntados sobre o que esses problemas poderiam trazer para eles, disseram que poderiam causar dengue, doenças. Antônio disse que deveriam ter mais postos de saúde. Continuamos a insistir nos porquês daqueles problemas. Olívia disse que achava que era assim, porque ninguém cuidava. E, então, alguns de seus colegas discordaram, falaram que não achavam que era só por isso. Márcia discordou e citou o exemplo de sua avó, que varre a rua e cuida do bairro. Questionei-lhes se em todo bairro era assim, e tendo a resposta negativa, perguntei o porquê de não ser. Não responderam. Perguntei, por fim, como aquelas situações poderiam ser diferentes, e Márcia disse que deveria cuidar mais do bairro, Olívia disse que o prefeito deveria fazer a parte dele (DIÁRIO DE CAMPO, 17/08/2017)

Consideramos, também, as imagens selecionadas para os encontros como textos. Nesse caso, o processo da leitura ocorria de maneira mais espontânea, em que cada estudante era convidado a falar o que percebia e interpretava acerca das imagens expostas. 
Apontamos, a partir do excerto recortado do diário de campo, uma experiência de leitura encharcada por uma "Pedagogia da Pergunta", porque não pretendeu preestabelecer respostas, mas suscitar a criatividade e a curiosidade crítica e epistemológica (FREIRE, 2014). Freire adverte-nos que, sem a aventura do perguntar, é impossível criar, pois "toda prática educativa que se funda no estandardizado, no preestabelecido, na rotina em que todas as coisas estão pré-ditas, é burocratizante e, por isso mesmo, antidemocrática" (FREIRE; FAUNDEZ, 1998, p. 28).

Em outro trecho do diário de campo, é retratada a discussão do direito à moradia, em que os leitores em formação se questionam e são questionados acerca das desigualdades nas condições de moradia e refletem sobre o local onde vivem.

Marcela contou que tinha visto pessoas morarem debaixo da ponte em um bairro da cidade. Perguntei a elas se sabiam por que essas pessoas moravam lá, e Mônica respondeu que era porque eram pobres. Vinícius afirmou: 'Eu sou pobre e não moro debaixo da ponte!' Henrique respondeu: 'É porque a família não ajuda!' Eu continuei a provocar: 'E por que não ajuda?’Não ajuda porque ela é ruim', respondeu João. 'E o governo, não faz nada?', perguntei novamente. 'Ah, o governo é lava-jato!', retrucou João. Conversamos sobre a percepção de João, deixando que os demais expusessem seus pontos de vista, e a discussão se encerrou com uma discussão sobre a vida nas favelas e a violência que pode existir nestes locais (DIÁRIO DE CAMPO, 11/06/2017).

No trecho em destaque, a partir da problematização proposta, observamos que os jovens sujeitos percebem a situação da pobreza ao seu redor e partem do micro (família) para perceber o contexto macro das desigualdades: um governo indiferente às situações que os tocam mais imediatamente e envolvido em escândalos de corrupção (o que demonstra, inclusive, a capacidade de relacionar a leitura/discussão à percepção de acontecimentos recentes e amplamente divulgados pela mídia). A conversa que se iniciou sobre o fato de pessoas morarem embaixo de pontes se alongou na discussão sobre a moradia em favelas e a violência naturalizada como inerente a esse contexto. 
O que se vê, portanto, é que, no processo de problematização,

cabe ao investigador, auxiliar desta, não apenas ouvir os indivíduos, mas desafiá-los cada vez mais, problematizando, de um lado, a situação existencial codificada e, de outro, as próprias respostas que vão dando àqueles no decorrer do diálogo. Desta forma, os participantes do 'círculo de investigação temática' vão extrojetando, pela força catártica da metodologia, uma série de sentimentos, de opiniões, de si, do mundo e dos outros, que possivelmente não extrojetariam em circunstâncias diferentes (FREIRE, 1987, p. 65).

Propusemos aos jovens, dessa maneira, uma forma outra de leitura, mediante a constante problematização da palavra, que lhes permitisse ler menos ingenuamente também a realidade circundante e dela se deslocarem, para, então, a ela voltarem com maior capacidade de crítica. Nesse movimento, acreditamos que os sujeitos se tornam capazes de intentarem um olhar menos superficial para sua realidade e podem melhor apreendê-la, observá-la e avaliá-la. Como discorre Freire (1985, p. 57), "os homens, em seu processo, como sujeitos do conhecimento e não como recebedores de um 'conhecimento' de que outro ou outros lhes fazem doação ou lhes prescrevem, vão ganhando a 'razão' da realidade”.

Em nossos Círculos de Leitura Crítica, experienciamos uma leitura viva, democrática, porque não imposta, mas construída em conjunto e grávida de sentidos críticos. Leitura que "cheira à liberdade, sem o ranço teorizante das salas de aula, nem a presença de um erudito centralizando as discussões" (SOUZA, 2012, p. 100). Essa leitura era representativa da realidade de vulnerabilidade social que os sujeitos dos círculos vivenciavam e, oportunizando a abstração da dura realidade, oportunizaram mais: a percepção consciente dos condicionantes sociais dessa realidade.

\section{Acabamentos da experiência $\mathrm{e}(\mathrm{m})$ abertura ao porvir}

$\mathrm{Na}$ composição da experiência extensionista que aqui apresentamos, compreendemos com Paulo Freire (1985) que a exten- 
são não pode ser aquela na qual se estende algo a alguém, para não cairmos no equívoco gnosiológico do termo extensão como ato de transmissão, doação, invasão cultural ou manipulação. Nossa busca, pelo contrário, foi pelo diálogo, pela troca de saberes, pelo respeito mútuo, pela reflexão partilhada e pelas aprendizagens construídas coletivamente. Por isso, comunicamos.

Para construirmos essa ação comunicativa, foi necessário experimentar um olhar mais aprofundado para o coletivo em situação de vulnerabilidade, visto que as vulnerabilidades são diversas e possuem particularidades, não se resumindo apenas a condições materiais. Nesse olhar, mais do que percebermos os condicionamentos relacionados à situação de vulnerabilidade social, procuramos enxergar, também, os anúncios de uma esperança radical despertada a partir da leitura crítica, que permite aos sujeitos a assunção de sua palavra própria.

Em um cenário de periferia desumanizadora, no qual vivenciar uma juventude saudável é enorme desafio, a leitura é ato político quando considera a visão de mundo de leitores e leitoras, não se configurando como uma imposição insensível ao contexto social por eles vivenciado. Nessa perspectiva, a metodologia de formação em Círculos de Leitura Crítica possibilitou, em nossa experiência, a horizontalidade no exercício de um diálogo que criticiza, porque problematiza.

Por nós, foi percebido que os Círculos de Leitura Crítica possibilitaram não apenas reflexões sobre os textos, mas também sobre a realidade concreta do cotidiano desses jovens, os quais se mostraram sujeitos atentos aos fatos sociais que vivenciam no dia a dia. Podemos dizer que os Círculos de Leitura Crítica foram bastante significativos para os jovens, que não só puderam dizer suas palavras, como ainda experimentaram, pela dinâmica dialógica dos círculos, maior interação pessoal e verbal entre todos, educador/a e educandos/as; e educandos e educandas entre si.

Nesse sentido, divisamos, como materialidades resultantes da proposta e que contribuem para o enfrentamento da realidade social vivida pelos sujeitos participantes, o fortalecimento de seu 
interesse e gosto pela prática da leitura e uma assunção mais clara das identidades pessoais e coletivas, especialmente no que tange às relações de gênero e raça, no interior das problematizações dos temas geradores, proporcionando a muitos dos sujeitos envolvidos a possibilidade de perceber-se criticamente e as implicações decorrentes da assunção dessa identidade.

E é com uma cena enunciativa tecida por um estudante negro de dez anos de idade, em que pudemos evidenciar o movimento de tomar-se como sujeito de palavra própria, no anúncio da "assunção cultural" (FREIRE, 2014) de sua identidade negra, que encontramos, talvez, a melhor imagem de um acabamento aberto ao porvir:

Rima do cuidado

Ter amor ao próximo, porque ele também é filho de Deus.

Somos todos iguais por causa da pele, cabelo, rosto.

Todos temos coração: racismo não!

Se liga, você gostaria se fosse com você? Sou preto com orgulho, meu irmão! (S., 10 anos).

Neste trabalho orientado pela práxis freireana, discutimos e vivenciamos novas possibilidades de formação leitora, que, partindo da realidade dos sujeitos, pudesse instrumentalizá-los para a luta contra a desumanização da qual são vítimas cotidianamente. Desse modo, mais do que percebermos os condicionamentos emersos da situação de vulnerabilidade social, procuramos enxergar, também, os anúncios de uma esperança radical despertada a partir da leitura crítica, a qual permite aos sujeitos a assunção de sua palavra própria.

$\mathrm{Na}$ travessia da experiência aqui analisada, não procuramos resultados traduzidos em números. Não procuramos, messianicamente, levar a salvação através da leitura. Não procuramos transplantar formas ou métodos. Não procuramos impor formas de leitura. Não procuramos grandes e imediatas transformações. Mas, cientes de que nossa ação responsiva possui força molecular, podemos dizer que cumprimos o que procuramos: excitar uma percepção crítica da realidade e dos condicionamentos que ela nos expõe, 
estimulando um necessário movimento para a transformação, resistência e enfrentamento às/das opressões contidas nas situações de vulnerabilidade social.

\section{Referências}

ABRAMO, H. W. Considerações sobre a tematização social da juventude no Brasil. Revista Brasileira de Educação, n. 5/6, p. 25-36, set/dez. 1997.

ADORNO, R.C.F. Os jovens e sua vulnerabilidade social. São Paulo: AAPCS, 2001. ASSOCIAÇÃO VIDA NOVA. Projeto político-pedagógico. s/l: s/n, s/d.

FREIRE, P. Extensão ou comunicação? 8. ed. Rio de Janeiro: Paz e Terra, 1985. Pedagogia do oprimido. 17. ed. Rio de Janeiro: Paz e Terra, 1987.

Pedagogia da esperança: um reencontro com a Pedagogia do Oprimido. Rio de Janeiro: Paz e Terra, 1992.

. A importância do ato de ler: em três artigos que se completam. 44. ed. São Paulo: Cortez, 2003.

Professora sim, tia não: cartas a quem ousa ensinar. 23.ed. Rio de Janeiro:Civilização Brasileira, 2012.

Pedagogia da autonomia: saberes necessários à prática educativa. 49. ed. Rio de Janeiro: Paz e Terra, 2014.

FREIRE, P.; FAUNDEZ, A. Por uma pedagogia da pergunta. 3. ed. Rio de Janeiro: Paz e Terra, 1998.

LARROSA, J. Tremores: Escritos sobre experiência. Belo Horizonte: Autêntica, 2014.

LOPES, R. E. et al. Juventude pobre, violência e cidadania. Saúde e Sociedade, v. 17, n. 3, p. $63-76,2008$.

RADO, S. C.; BONETI, L. W. A juventude em condições de vulnerabilidade social e as políticas de acesso à educação. In: IX Congresso Nacional de Educação Educere - III Encontro Sul Brasileiro de Psicopedagogia. Anais. PUC/ PR. Paraná, 2009. Disponível em: <https://educere.bruc.com.br/arquivo/ pdf2009/3032_1578.pdf>. Acesso em: 14 de agosto de 2018. 
SOUZA, R. M. Leitores, leitura e círculos: Uma perspectiva metodológica. Ponto de Acesso, v. 6, n. 1, p. 92-107, 2012.

TEIXEIRA, E. C. Resiliência e vulnerabilidade social: uma perspectiva para a educação sociocomunitária da adolescência. 2015. Dissertação (Mestrado em Educação) - Centro Universitário Salesiano de São Paulo, Americana, 2015.

VASCONCELOS, M. L. M. C.; BRITO, R. H. P. de. Conceitos de educação em Paulo Freire. 6. ed. Petrópolis: Vozes; São Paulo: Mack, 2014. 